\title{
CORPOREIDADE NO SISTEMA PRISIONAL
}

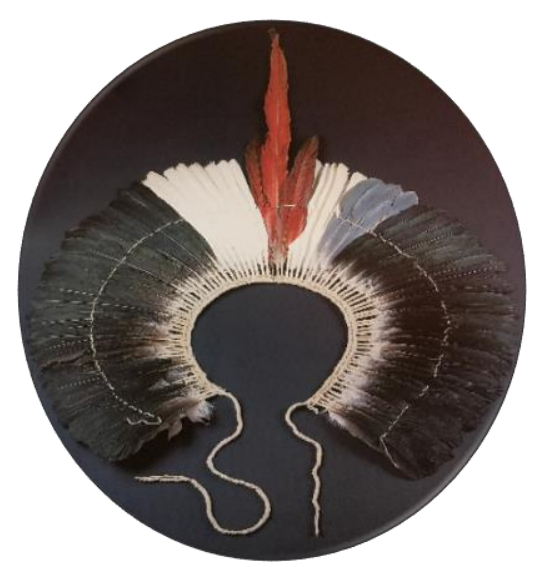

Raimundo Pereira Pontes Filho ${ }^{1}$ João Bosco Ladislau de Andrade ${ }^{2}$

RESUMO: Este artigo pretende discutir a corporeidade nos estabelecimentos penitenciários, tomando como referência o sistema prisional brasileiro, em especial o vigente no estado do Amazonas. Para tanto, a partir de visitas técnicas a estabelecimentos prisionais dessa unidade federativa, observou-se o comportamento dos detentos, a linguagem de sua relação com o corpo no cárcere, mediada pela poder da violência e do medo, e dialogou-se com eles. Levantaram-se dados oficiais acerca da realidade prisional no país. Ao final, aponta-se aquilo que essa pesquisa considera as principais características da corporeidade no interior do sistema prisional.

PALAVRAS-CHAVE: Corporeidade. Sistema prisional. Linguagem do cárcere. Cultura do crime.

\footnotetext{
${ }^{1}$ Doutor em Sociedade e Cultura na Amazônia (UFAM)

2 Engenheiro Civil; Doutor em Hidraulica e Saneamento (USP); Professor do Programa de Pós-Graduação em Sociedade e Cultura na Amazônia, da Universidade Federal do Amazonas (UFAM)
} 


\section{INTRODUÇÃO}

$\mathrm{Na}$ busca de possibilidades de ressocialização para reinserção social dos presos $^{3}$, bem como de alternativas ao modelo de encarceramento ineficaz, violento e oneroso que se mantém no Brasil, compreender a corporeidade prevalecente no sistema prisional é um ponto de partida relevante nessa difícil tarefa.

$\mathrm{E}$ o que se entende por corporeidade? O que caracteriza a corporeidade nos presídios? Qual a linguagem da corporeidade predominante no sistema prisional brasileiro? O que implicaria ao sistema prisional trabalhar intervenções e programas de ressocialização para reinserção social de presos que considerassem a noção de corporeidade?

\section{ASPECTOS METODOLÓGICOS}

Entender essa linguagem que prevalece nos cárceres, não limitada à expressão oral, constitui-se numa possibilidade relevante para entender a corporeidade nos presídios do país. Requer não apenas deduções teóricas, mas conhecimento empírico dessa impactante faceta da realidade social, cujos efeitos se fazem sentir na área econômica, política e institucional.

Temos realizado muitas visitas em estabelecimentos penais, particularmente no estado do Amazonas. Por meio delas, testemunhamos que, embora existam especificidades, o encarceramento praticado nessa unidade federativa não difere tanto dos demais estados do país, tendo em conta o que se pode observar de suas administrações penitenciárias e também pelo que temos acompanhado como presidente do Conselho Penitenciário estadual.

${ }^{3}$ Finalidade última da execução penal, conforme o art. $1^{\circ}$. da Lei $n^{\circ}$. 7.210/84 (LEP). 
Obviamente há realidades prisionais com maiores carências assistenciais, violência, deficiências logísticas e infraestruturais de um estado em relação a de outros. Contudo, em que pesem essas diferenças, elas não invalidam tomar-se o caso do sistema prisional do estado do Amazonas como um parâmetro para fins de estudo e análise sobre a corporeidade no sistema prisional brasileiro. Considerando esse propósito, o sistema prisional do Amazonas acaba sendo uma amostra válida, afinal, são diversas unidades prisionais, que lidam todos os dias com uma massa de indivíduos encarcerados.

Por meio dessas visitas aos estabelecimentos penais, pode-se observar o comportamento dos detentos e a linguagem de sua relação com o corpo no cárcere, bem como dialogar com alguns presos do sistema prisional. Paralelo a isso, levantaram-se dados oficiais acerca da realidade prisional do país. Ao final, procurou-se apontar as principais características da corporeidade no interior do sistema prisional amazonense.

Vejamos os dados a seguir quanto aos estabelecimentos prisionais e à população carcerária do estado do Amazonas:

\section{Estabelecimentos Prisionais na Capital - Manaus (dados da}

\section{Sejus/AM-2014):}

1. Cadeia pública masculina Raimundo Vidal Pessoa

2. Cadeia pública feminina Raimundo Vidal Pessoa

3. Hospital de Custódia

4. Casa do Albergado de Manaus

5. Complexo Anísio Jobim (Compaj) - regime semiaberto

6. Complexo Anísio Jobim (Compaj) - regime fechado masculino

7. Complexo Anísio Jobim (Compaj) - regime fechado feminino

8. Unidade Prisional do Puraquequara - UPP

9. Centro de Detenção Provisória de Manaus - CDPM 
10. Centro de Detenção Provisória Feminina - CDPF (inaugurada em junho/2014)

11. Instituto Penal Antônio Trindade - IPAT

12. Penitenciária Feminina de Manaus

13. Presídio da Polícia Militar

14. Unidade prisional do Comando de Policiamento Especial CPE

Outros municípios com unidades prisionais (dados da Sejus/AM2014):
1. Coari
2. Humaitá
3. Itacoatiara - regime fechado
4. Itacoatiara - mista
5. Manacapuru
6. Maués
7. Parintins
8. Tabatinga
9. Tefé

Demais municípios - ausência de estabelecimentos penais (dados da Sejus/AM-2014):

A Delegacia de Polícia de cada Município, que não dispõe estabelecimento algum para cumprimento da execução penal, tem operado concretamente como carceragem, totalizando 52 unidades de Polícia Judiciária que funcionam como unidade encarceradora. 
População carcerária do Amazonas, em outubro/2014 (dados da Sejus/AM-2014):

Total: 9.211 presos

Condenados: $4.173(45 \%)$

Provisórios: $5.038(55 \%)$

Capital: 6.050

Interior: 3.161

Homens: 8.562

Mulheres: 649

Vagas existentes: 3.489 vagas

Excedentes: faltam 5.722 vagas

Percentual do déficit de vagas no sistema: $164 \%$

\section{NOÇÕES DE CORPOREIDADE}

Por corporeidade tomamos a noção exposta na obra de Marcel Mauss - "Sociologia e Antropologia: noção de técnica do corpo", para quem o corpo deve ser pensado para além de sua dimensão biológica, embora seja parte integrante da natureza. Para Mauss, técnicas corporais são maneiras como as pessoas empregam seus corpos no interior de uma sociedade (como andam, sentam, comem, falam, olham, riem, gesticulam etc). Dito por ele mesmo: "maneiras pelas quais os homens, de sociedade a sociedade, de uma forma tradicional, sabem servir-se de seu corpo. Em todo caso, convém proceder do concreto ao abstrato, não inversamente.” (1974, p.401). Com isso, Marcel Mauss começou a demolir a separação entre natureza e cultura para formar uma nova concepção de corpo, fundamento da moderna noção de corporeidade.

Até o século XIX, via-se o corpo apenas como obra da natureza, dissociado da mente e mesmo uma prisão à alma, conforme entendeu Platão. O racionalismo de Descartes tratou de aprofundar a visão dicotômica entre corpo x mente, natureza x cultura, físico x espiritual, de modo a distanciar ainda mais a sensibilidade da racionalidade. E o corpo acabou sendo entendido e tratado até o século XIX somente como realidade natural, algo que existia como uma máquina, a ser controlada e sujeitada a uma disciplina 
útil à produção e à exploração pela economia, pela política, pela vida social. Somente na segunda metade do séc. XIX, por meio de Mauss e de Nietzsche, retomou-se a ideia de um corpo uno, resultado da integração entre natureza e sociedade, físico e mental, razão e sensação. A visão dicotômica passou a ser questionada por uma concepção mais holística do corpo, da qual serão expoentes, no séc. XX, Merlau-Ponty e Michel Foucault.

Merlau-Ponty reconhece que, nesse mundo, a existência humana só é possível por meio de um corpo, que é mental e físico, pensamento e sentimento simultaneamente, muito mais que um mero conjunto de músculos e ossos, mas que é o próprio atuar do indivíduo sobre a sociedade e que revela diversos aspectos da vida em sociedade. No entendimento do fenomenólogo, "a cultura cientifica ocidental requer que tomemos os nossos corpos simultaneamente como estruturas físicas e como estruturas experienciais vividas - em suma, tanto como externos como internos, biológicos e fenomenológicos" A articulação entre essas estruturas é a condição da corporeidade, que consiste numa nova concepção de corpo que integra a natureza à cultura, o material ao imaterial, o físico ao mental, o individual ao social. Uma interpretação holística de corpo que supera a velha visão dicotômica, abrindo caminho para uma nova compreensão de homem e de mundo.

Nesse sentido, Michel Foucault radicaliza a crítica à interpretação dicotômica de corpo ao afirmar que "alma é a prisão do corpo", em antagonismo a Platão e a Descartes, entendendo que a visão mecânica do corpo submeteu-o a uma disciplina e controle para os quais "o corpo só se torna força útil se é ao mesmo tempo corpo produtivo e corpo submisso." Por isso, a necessidade de uma interpretação do corpo, que recupere sua dimensão holística, una e simultaneamente libertária é tão essencial, o que se busca com a noção de corporeidade.

Compreender a corporeidade nos presídios é, por essa razão, algo que vai além do corpo físico e natural, alcançando elementos da cultura criminógena dos cárceres, cuja linguagem cotidiana, oral e não-oral, é 
instrumento relevante para entender as possibilidades e os desafios para implantar um processo de ressocialização no sistema prisional, com vistas à reinserção social do preso.

\section{CONTEXTO DO CÁRCERE}

É importante retomar algumas características do contexto sobre o qual estamos falando para compreender essa linguagem indicativa de elementos da corporeidade no cárcere.

No Brasil, segundo o relatório da CPI do sistema carcerário (2009), que realizou amplo levantamento da situação das cadeias e presídios brasileiros, os cárceres são depósitos de gente descartável e que funcionam de modo a perpetuar a barbárie. Prender, mesmo em condições deploráveis, é lucrativo e movimenta a economia de mercado, em especial com aqueles que foram excluídos dela, e que não têm mais espaço nela. Os estabelecimentos penais operam, via de regra, superlotados. A superlotação é motivo de brigas e rebeliões e, muitas vezes, de morte para abrir vaga na cela. Não há espaço mínimo para uma convivência segura nem saudável nos cárceres do país, muito menos para uma convivência ressocializadora, como preconiza a lei de execução penal brasileira.

Os presos são lançados numa ociosidade que opera em favor do crime, em cárceres quase sempre comandados por facções criminosas. A estrutura e o espaço físico estão aquém do que estabelecem as normas nacionais e internacionais. Programas de educação ou qualquer outra ocupação para ressocializar os presos, quando raramente existem, não cumprem sequer razoavelmente o propósito a que se destinam nem se importam com a eficácia dos mesmos. A higiene, o trabalho e as condições de segurança nos presídios são precárias, assim como a assistência médica, quase sempre irrisórias dentro das unidades que compõem o sistema penitenciário no país. Há unidades prisionais, como as de segurança máxima, 
em que a assistência médica é prestada apenas com o paciente algemado e em ala dominada por facção rival.

Diante dessas e outras precariedades, as facções criminosas se fortalecem, ofertando assistências, alguma segurança e certas "regalias" em troca do recrutamento de presos à economia do crime, ditando o ritmo e a intensidade da violência e das rebeliões, bem como apoiando as frequentes fugas dos presídios. Elas conseguem fazer com que drogas, armas, celulares e outras coisas continuem a entrar nas unidades do sistema prisional do país. Tais facções converteram-se, hoje, em fatores de insegurança não apenas dentro, mas principalmente fora dos presídios, praticando delitos arquitetados a partir do interior dos cárceres. É praticamente impossível a qualquer preso, nos dias atuais, cumprir sua pena sem ser forçado a fazer parte dessas facções criminosas. Uma vez integrantes das mesmas, os ingressos e egressos do sistema prisional passam a contar com "o bônus e o ônus" dessa fidelização à facção do crime a qual aderiu.

De acordo com levantamento do CNJ, divulgado recentemente, no dia 4/6/2014, o Brasil subiu mais uma posição no lamentável ranking dos países com maior população carcerária. Agora é o terceiro Estado com mais gente encarcerada. Um nítido exemplo de que apenas política repressiva, voltada para o encarceramento em massa, não é sinônimo de segurança pública.

Ultrapassamos a Rússia, que conta com mais de 680 mil presos, alcançando a indesejável cifra de mais de 715 mil presos. Para tanto, bastou contabilizar um número que antes não era levado em consideração no computo total de presos no Brasil: 148 mil pessoas em prisão domiciliar. Somados aos demais de 567 mil encarcerados, chegou-se à nova estatística. Em matéria de população carcerária, ficamos agora atrás somente dos EUA (mais de 2,2 milhões de presos) e da China (com cerca de 1,7 milhão de encarcerados). 
A quase totalidade dos encarcerados é constituída de pessoas pobres, jovens e de baixa escolaridade. Muitos nem deveriam mais estar na unidade prisional, expostos a tantos riscos capitais, pois são presos provisórios ou ainda aqueles cujo excesso de prazo já lhes confere o direito a deixar o cárcere. Esse último aspecto evidencia a morosidade do processo judicial criminal e a dificuldade de satisfação da garantia à assistência jurídica.

Um preso custava ao Estado brasileiro, em 2007, entre R $\$ 1.800,00$ e R $\$ 2.100,00$ mensais, cerca de dez vezes mais do que se gastava com uma criança na escola pública.

O resultado do atual modelo de sistema prisional em vigor no país tem sido a produção de seres embrutecidos, truculentos, ensandecidos, bipolares, constituindo-se numa eficaz fábrica de doentes, psicopatas, doidos, latrocidas, homicidas e outros desviantes potencializados pelas condições humilhantes e degradantes de unidades do sistema prisional do país.

Outra consequência é uma espécie de assepsia prisional, sob as vistas grossas do Estado e da sociedade, decorrente do número de mortos nas prisões brasileiras: em 2007, foram 1.250 mortes, segundo levantou a CPI que investigou o sistema carcerário. Uma média anual de três mortos ao dia. Agentes carcerários são também surpreendidos ocasionalmente, sendo por vezes vitimados de modo fatal.

Um sistema prisional bastante oneroso à sociedade e que radicaliza na linguagem do descarte, da violência e do crime, potencializando o indivíduo na carreira do crime, sendo fator mais insegurança pública do que de garantia de liberdade e do usufruto de outros direitos pela sociedade.

\section{CORPOREIDADE NOS PRESÍDIOS}

A linguagem predominante nos presídios nos diz muito acerca da corporeidade que se reproduz nos mesmos. 
Nota-se, sob distintas formas de expressão, a prevalência de uma linguagem da violência, inclusive como forma de reforçar os valores da chamada cultura criminógena ou ambiência do crime. Uma linguagem da provocação, da sujeição e da dominação pela imposição da força e do medo. Linguagem essa que alimenta e pereniza o estado de ameaça e de terror dentro da unidade prisional, decorrendo disso o poder de mando das facções e seus "líderes", chamados "xerifes" ou ainda "prefeitos", os quais comandam assim um estabelecimento carcerário.

Esse chefe, quase sempre representante de uma facção criminosa, define e reproduz o bônus e o ônus à população carcerária, recorrendo à linguagem da intimidação, da submissão e da violência. A população carcerária termina por "aceitar" essa imposição da violência, conferindo assim certa "legitimidade" a essa dominação violenta e ilegítima.

A linguagem da violência dos presídios reproduz não apenas a cultura do crime no interior dos cárceres, como também de fora deles, extramuros, na sociedade, reforçando, com isso, os "valores" da economia do crime, a cultura criminógena. Eles se manifestam de diversas formas, tais como:

a) culto à força da violência imposta pela ação criminosa;

b) valorização do medo e da obediência pela imposição da força do crime;

c) sujeição da população ao chefe, "xerife" ou "prefeito" da unidade prisional, em regra vinculado ou mesmo comandante de grupo ou facão criminosa;

d) culto ao armamento e ao suposto poder das armas;

e) identidade (personagem ou máscara) vinculada ao crime praticado, principalmente quando o delito é de maior gravidade, que reforce a ideia de elemento que merece "respeito" junto aos demais indivíduos da comunidade de presos; 
f) poder de dispor e consumir o corpo do outro no interior do cárcere, inclusive na condição análoga a de escravo, considerando ainda a posse e uso sexual do corpo do outro. Ocorre, muitas vezes, em face disso, a redefinição da orientação sexual de homens e de mulheres;

g) coisificação do sexo como negócio e moeda de troca no interior do cárcere;

h) ostentação de símbolos de status e de consumo no cárcere: joias, drogas, celulares, roupas de marca, perfumes, relógios, tv's na cela, tipos de cabelo, acesso a um maior número de visitas íntimas e outros;

i) linguagem violenta: fala agressiva, tipos de gíria, tatuagens, corte de cabelo, gestos, trejeitos, vocabulário, códigos internos, códigos de grupos ou de facções;

j) busca de manifestar poder por meio de intervenção sobre o próprio corpo, incluindo processos de deformação corporal - certos tipos de uso de piercings, acessórios, tatuagens etc.

As condições do contexto dos cárceres no Brasil, expostas anteriormente, concorrem, sobremaneira, no sentido de agravar situações e cenários nos quais se manifestam essa linguagem de violência e da cultura criminógena, caracterizadoras dessa corporeidade expressa e vivenciada no interior das unidades prisionais.

\section{CONSIDERAÇÕES FINAIS}

A linguagem, seja oral seja comportamental ou corporal, é um processo social imprescindível como instrumento indicativo das características da corporeidade do sistema prisional.

Ela revela muito sobre as condições, os valores e as atitudes individuais nos cárceres, assim como sobre os valores da cultura criminógena predominante nos presídios. 
A compreensão da corporeidade nos estabelecimentos prisionais é de grande relevância para se nortear a busca de processos de ressocialização das pessoas encarceradas, bem como tendo em vista a formulação de intervenções gerenciais nos mesmos, no sentido de implantar programas e ações no interior dos cárceres, voltados à população de presos, sejam eles provisórios ou condenados.

A opção por intervenções e trabalhos que considerem os elementos da corporeidade nos presídios implica inevitavelmente na revisão do atual modelo de encarceramento adotado, fundado apenas no princípio moralista de penitência expiatória, de castigo e de prisão punitiva, quase sempre descomprometido com a recuperação e a ressocialização do aprisionado, com vistas à sua reinserção na convivência social livre e lícita. A ideia de trabalhar com programas de reabilitação de presos do sistema a partir da noção de corporeidade demanda uma reavaliação do marco legal e do sistema prisional em vigor. Requer ações e medidas de tratamento psicossocial, intervenções terapêuticas que trabalhem para promover a saúde mental e a educação emocional, afetiva, sexual, cívica, voltada para o convívio em liberdade e o compromisso com uma cultura de licitude. Exige uma contrapartida desse sistema no sentido de servir efetivamente à sociedade, promovendo segurança, e não sendo fator de maior insegurança e práticas delituosas, planejadas a partir de dentro dos estabelecimentos prisionais.

Apesar de tudo, o objetivo maior, o ideal ou mesmo a utopia é que não precisasse a sociedade de um sistema prisional nem insistisse no modelo que tem adotado. Muito já se postulou sobre o assunto e acerca da completa falência do mesmo para ressocializar encarcerados com vistas à reinserção social. Entretanto, mesmo sendo conhecedores de toda onerosidade, violência, risco e ineficácia dos presídios, talvez porque a sociedade não queira pôr outra coisa em seu lugar ou não visualize outra possibilidade, a prisão continua sendo a principal medida penal. A prisão não é coadjuvante, mas atriz principal na cena do sistema de justiça criminal no país. 


\section{REFERÊNCIAS}

BECCARIA, Cesare. Dos Delitos e das Penas. $5^{\text {a }}$. reimpressão. São Paulo: ed. Martin Claret, 2008.

BRASIL, Câmara dos deputados. Relatório da CPI do Sistema Carcerário. Biblioteca digital da Câmara dos deputados, 2009. (http://bd.camara.gov.br).

BRASIL. Lei de Execução Penal: Lei $\mathbf{n}^{\mathbf{0}}$. 7.210/1984. (www.planalto.gov.br).

FOUCAULT, Michel. Vigiar e punir: nascimento da prisão. $20^{\mathrm{a}}$.ed. Rio de Janeiro: Petrópolis, 1987.

Edições Graal, 1992.

Microfísica do Poder. 10a . ed. Rio de Janeiro:

MAUSS, Marcel. Sociologia e Antropologia. Edição em cópia eletrônica: http://oficinasociologica.blogspot.com.br/2012/03/downloads-de-livrosde-sociologia.html.

RODRIGUES, Rogério. Sociedade, Corpo e Interdições: contribuições do estudo de Marcel Mauss sobre as técnicas do corpo. Revista Brasileira de Ciência do Esporte, jan/maio, 2000.

SANT'ANNA, Denise Bernuzz de. É possível realizar uma história do corpo? In: Carmem Lúcia Soares (organizadora). Corpo e história. Campinas, SP: autores associados, 2001.

SANTIN, Silvio. Perspectivas na visão da corporeidade. In: Ademar Gebara et al. (organizadores). Educação física e esporte: perspectivas para o século XXI. Campinas, SP: Papirus, 1993.

SEJUS/AM (Secretária de Justiça, Cidadania e Direitos Humanos do Amazonas). Dados oficiais acerca dos estabelecimentos prisionais e da população carcerária. Maio/2014. 